\title{
$\mathrm{HBr} / \mathrm{Ar} / \mathrm{CHF}_{3}$ 혼합가스를 이용한 $\mathrm{ZnO}$ 박막의 유도결합 플라즈마 식각
}

\author{
김문근 ${ }^{1}$, 함용현 ${ }^{1}$, 권광호', 이현우,a \\ 1 고려대학교 제어계측공학과 \\ 2 한서대학교 전자 · 컴퓨터 · 통신학부
}

\section{Etching Characteristics of $\mathrm{ZnO}$ Thin Films Using Inductively Coupled Plasma of $\mathrm{HBr} / \mathrm{Ar} / \mathrm{CHF}_{3}$ Gas Mixtures}

\author{
Moonkeun Kim ${ }^{1}$, Young-Hyun Ham ${ }^{1}$, Kwang-Ho Kwon ${ }^{1}$, \\ and Hyun Woo Lee Lea $^{2,}$ \\ ${ }^{1}$ Department of Control and Instrumentation Engineering, Korea University, Sejong 339-700, Korea \\ ${ }^{2}$ Division of Electronic, Computer, and Communication Engineering, Hanseo University, Seosan 356-706, Korea
}

(Received September 10, 2010; Revised October 26, 2010; Accepted October 28, 2010)

\begin{abstract}
In this work, the etching characteristics of $\mathrm{ZnO}$ thin films were investigated using an inductively coupled plasma(ICP) of $\mathrm{HBr} / \mathrm{Ar} / \mathrm{CHF}_{3}$ gas mixtures. The plasma characteristics were analyzed by a quadrupole mass spectrometer (QMS) and double langmuir probe (DLP). The surface reaction of the $\mathrm{ZnO}$ thin films was investigated using $\mathrm{X}$-ray photoelectron spectroscopy (XPS). The etch rate of $\mathrm{ZnO}$ was measured as a function of the $\mathrm{CHF}_{3}$ mixing ratio in the range of $0-15 \%$ in an $\mathrm{HBr}: \mathrm{Ar}=5: 2$ plasma at a fixed gas pressure $(6 \mathrm{mTorr})$, input power $(700 \mathrm{~W})$, bias power $(200 \mathrm{~W})$ and total gas flow rate $(50 \mathrm{sccm})$. The etch rate of the $\mathrm{ZnO}$ films decreased with increasing $\mathrm{CHF}_{3}$ fraction due to the etch-blocking polymer layer formation.
\end{abstract}

KeyWords: ZnO, XPS, Etching, ICP, Langmuir probe

\section{1. 서 론}

최근 태양전지, $\mathrm{ZnO}$ 및 $\mathrm{GaN}$ 계열의 발광소자, lipuid crystal display (LCD), plasma display panel (PDP) 및 organic luminescent emitting display (OLED) 와 같은 대형 평판디스플레이 (FPD) 등의 광전자산업 분야가 급속히 발전함에 따라 투명도와 전기전도도가 높은 투명 전도성 산화막 (transparent conductive oxide, TCO) 에 대한 연구가 활발히 진행 되고 있다. 현재 투명전도성 산화막으로 가장 많이

a) Corresponding author : hwlee@hanseo.ac.kr
알려져 있고, 상용화되고 있는 것은 indium-tin oxide (ITO) 로 전도성이 우수하고 (비저항: $10^{-4} \Omega \mathrm{cm}$ ), 동 시에 광투과도도 가시광선 영역에서 $80 \%$ 이상으로 전기 광학적 특성이 우수한 장점이 있다. 하지만 ITO 의 주요 구성 원소인 In 은 존재량이 매우 희박하며, $\mathrm{Zn}$ 이나 $\mathrm{Pb}$ 의 생산 부산물로 얻어지기 때문에 공급 량이 한정되어 있다. 또한 ITO 박막이 낮은 비저항과 높은 투과율을 나타내기 위해서는 $200 \sim 300^{\circ} \mathrm{C}$ 이상의 고온에서 박막이 성장해야 한다. 또한, 유연성이 큰 플라스틱 기판에 박막을 증착할 경우에는 고온의 증 착환경이 기판 자체를 손상 시킬 수도 있고, $100^{\circ} \mathrm{C}$ 이하의 저온에서는 성장된 비정질 ITO 박막은 습열 
(moist heat)에 대한 저항력이 매우 약하다고 알려져 있다. 이에 반해 $\mathrm{ZnO}$ 는 적외선 및 가시광선 영역에 서의 투과성 및 전기 전도성과 플라즈마에 대한 내구 성이 우수하고, 낮은 온도에서 공정이 가능하며 원료 가격이 비교적 낮아서 대면적 디스플레이 투명전극용 또는 윈도우용 재료로서 ITO를 대체하려고 국내외에 서 현재 많이 연구되고 있는 실정이다[1-3]. $\mathrm{HBr}$ 가 스는 $\mathrm{ZnO}$ 박막과 하부층 또는 포토 레지스트의 선택 비와 식각 프로파일을 향상 시키기 위해 사용되어져 왔다[4]. 본 연구진은 $\mathrm{HBr} / \mathrm{Ar}$ 혼합기체를 사용하여 $\mathrm{ZnO}$ 박막 식각에 대해 연구하여, $\mathrm{Br}$ 원자가 식각의 주 화학적 활성종이며 반응율-제한 식각이 주 식각 메커니즘이라고 보고한 바 있다[5].

본 연구에서는 먼저 $\mathrm{HBr} / \mathrm{Ar} / \mathrm{CHF}_{3}$ 플라즈마를 quadrupole mass spectrometer (QMS)를 이용하여 플라즈마 내에 형성되는 활성종을 분석하였다. 또한 식각 반응을 확인하기 위하여 시각된 시료의 표면을 $\mathrm{X}$-ray photoelectron spectroscopy (XPS) 분석을 통 해 확인하였다. 이러한 실험 결과를 바탕으로 $\mathrm{HBr} / \mathrm{Ar}$ / 에 $\mathrm{CHF}_{3}$ 가스를 추가에 의한 $\mathrm{ZnO}$ 박막의 식각 메커 니즘를 해석하였다.

\section{2. 실험 방법}

본 연구에서는 $\mathrm{ZnO}$ 박막을 식각하기 위하여 고 진공 하에서 고밀도 플라즈마를 형성하는 inductively coupled plasma (ICP) 식각 장비를 사용하였다[6]. 플 라즈마 생성을 위해 챔버 상부에 유도 코일이 감겨져 있으며, $13.56 \mathrm{MHz}$ 의 $\mathrm{RF}$ 전원이 인가된다. 마찬가 지로 하부 척에도 또 하나의 $12.56 \mathrm{MHZ}$ 의 $\mathrm{RF}$ 전원 이 인가되어 독립적으로 식각될 박막에 수직으로 입 사되는 이온의 에너지를 조절한다.

$\mathrm{ZnO}$ 박막은 (100) 실리콘 기판 위에 $\mathrm{RF}$ magnetron sputtering 방식으로 $99.99 \% \mathrm{ZnO}$ 타겟을 사용하여 증착 하였으며, 이 때 스퍼터 장비의 증착 압력은 40 mTorr, 파워는 $100 \mathrm{~W}$ 로 유지 하였으며, $20 \mathrm{sccm}$ 의 $\mathrm{Ar}$ 가스 $10 \mathrm{sccm}$ 의 $\mathrm{O}_{2}$ 가스를 혼합하여 증착하 였다. $\mathrm{ZnO}$ 박막은 $200 \mathrm{~nm}$ 두께로 증착 하였다.

식각 가스의 총 유량, 소스 파워, 바이어스 파워, 챔버 압력은 $50 \mathrm{sccm}, 700 \mathrm{~W}, 200 \mathrm{~W}, 6 \mathrm{mTorr}$ 로 고정 하였다. $\mathrm{HBr} / \mathrm{Ar}$ 의 가스 혼합 비율은 $5: 2$ 로 고정 하였으며 $\mathrm{CHF}_{3}$ 의 유량은 최대 $8 \mathrm{sccm}$ 이며 0-15\% 혼합 비율을 조절 하여 실험을 진행 하였다.

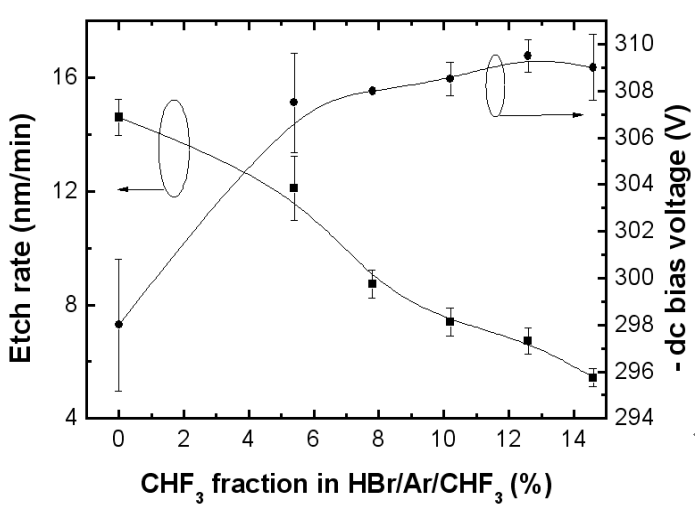

Fig. 1. Etch rate of $\mathrm{ZnO}$ thin film and self dc bias power as a function of $\mathrm{CHF}_{3}$ mixing ratio.

식각 전후 $\mathrm{ZnO}$ 박막 조성비와 식각 특성을 알아보 기 위하여 XPS 분석을 하였으며, 플라즈마 내에서 chemical species 의 특성을 조사하기 위하여 QMS (HIDEN, HPR-30, America)를 통한 부분 압력을 추 출 하였다. 식각된 $\mathrm{ZnO}$ 박막의 두께는 surface profiler (Tencor Instrument, Alpha step 500, America) 를 이용하여 측정하였다.

\section{3. 결과 및 고찰}

$\mathrm{ZnO}$ 박막은 $\mathrm{HBr} / \mathrm{Ar}$ 가스의 혼합 비율을 $5: 2$ 일 때 가장 높은 선택비를 갖는다.[4] 따라서 그림 1에서 는 혼합비율을 $5: 2$ 고정 후 $\mathrm{CHF}_{3}$ 가스의 비율을 증 가 시키면서 $\mathrm{ZnO}$ 박막의 식각 속도와 self dc bias 전압을 나타낸 것이다.

$\mathrm{ZnO}$ 박막의 식각 속도는 $\mathrm{CHF}_{3}$ 가스의 양이 증가 함에 따라 식각 속도는 감소하였다. $\mathrm{ZnO}$ 박막에서의 최대 식각속도는 $\mathrm{CHF}_{3}$ 가스 첨가하지 않았 때의 $14.5 \mathrm{~nm} / \mathrm{min}$ 이였다. 또한 $\mathrm{ZnO}$ 박막의 가스 혼합비에 따른 물리적인 효과가 식각 속도에 미치는 영향을 알 아보기 위하여 self bias voltage를 추출하였으며, $\mathrm{CHF}_{3}$ 가스의 양이 증가 함에 따라 전압은 $-298 \mathrm{~V}$ 에 서 $-309 \mathrm{~V}$ 로 절대값이 증가함을 확인하였다. Self dc bias와 식각속도는 반대되는 경향을 보이는데, 이는 가속된 이온의 표면과의 충돌에 의한 물리적인 식각 보다는 라디칼 등의 표면과의 화학반응에 의한 화학 적인 식각이 일어나는 것으로 추론된다.

그림 2 에서 보듯이 Langmuir probe를 이용하여 동 일한 조건에서 측정된 포화 이온 전류 밀도는 $\mathrm{CHF}_{3}$ 의 농도가 증가함에 따라서 증가하였고. 이는 플라즈 


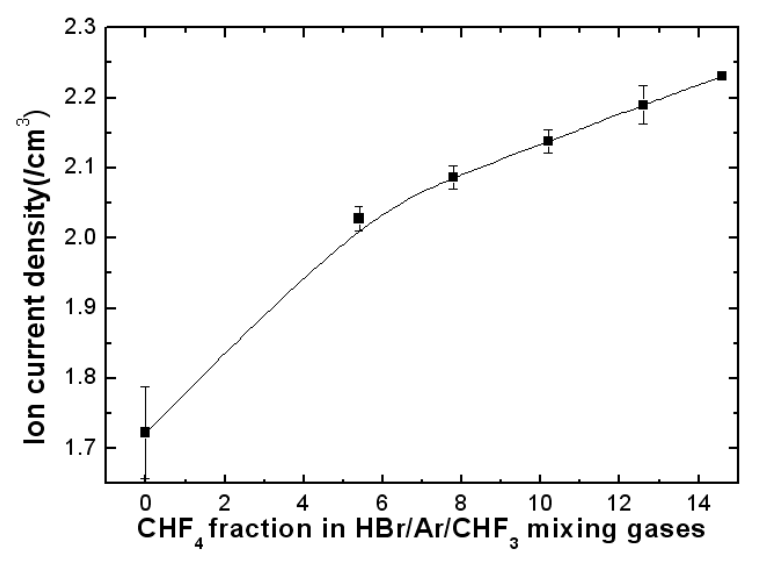

Fig. 2. Ion saturation current measured by Langmuir probe as a function of gas ratio of $\mathrm{CHF}_{3}$.

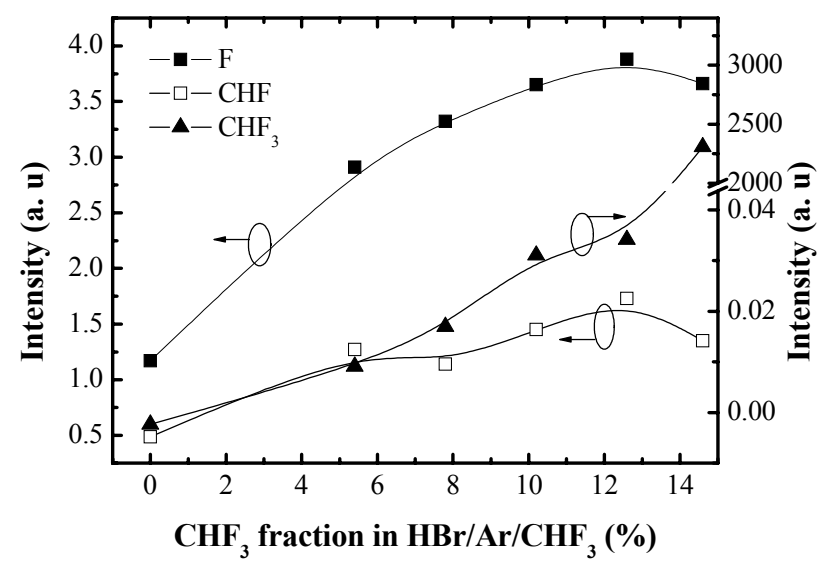

Fig. 3. QMS output partial pressure of neutral species of $\mathrm{CHF}_{3}$ mixing ratio.

마내의 이온 밀도의 증가가 그 원인이다.

Self bias voltage와 포화 전류 밀도가 증가하는 경 향과 반대로 식각 속도가 감소하는 원인을 규명하고 자 $\mathrm{QMS}$ 를 이용하여 $\mathrm{HBr} / \mathrm{Ar} / \mathrm{CHF}_{3}$ 플라즈마의 중성 종을 분석하였다. $\mathrm{QMS}$ 에서 $\mathrm{CHF}, \mathrm{F}, \mathrm{Br}$ 으로 분해됨 이 확인되었으며, 그림 3 에서 이 중에서 $\mathrm{F}, \mathrm{CHF}$, $\mathrm{CHF}_{3}$ 라디칼이 식각 가스 조합에 대한 상대적인 변 화를 나타내고 있다. $\mathrm{HBr} / \mathrm{Ar}$ 분위기에서 $12 \%$ 에서 $\mathrm{F}$, $\mathrm{CHF}$ 라디칼이 증가하나 그 이상 첨가시 일정하게 유 지되는 경향을 보인다. 반면 $\mathrm{CHF}_{3}$ 라디칼은 농도에 따라 증가하였다.

$\mathrm{CHF}_{3}$ 의 혼합비가 증가함에 따라 $\mathrm{ZnO}$ 박막의 식 각속도는 감소하였다. 이는 $\mathrm{CHF}_{3}$ 의 혼합비가 증가

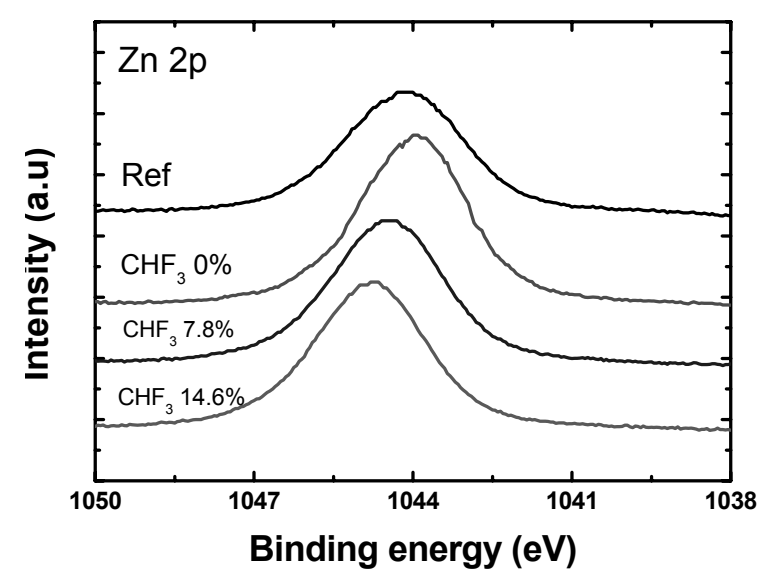

Fig. 4. XPS narrow scan spectra of $\mathrm{Zn} 2 \mathrm{p}$ from $\mathrm{ZnO}$ surfaces etched with CHF3 gas mixing ratio.

함에 따라 fluorine 라디칼의 부분압의 증가로 인하여, 보다 많은 fluorine 라디칼이 $\mathrm{ZnO}$ 박막의 표면에 흡 착되어 식각을 막는 폴리머를 형성하여 식각 속도를 감소시키는 것으로 판단되며 이를 XPS로 확인하였 다.[6]. $\mathrm{CHF}$ 라디칼의 경우에는 $\mathrm{CHF}_{3}$ 가스의 양과 무관하여 크기의 변화가 없으므로 식각에 큰 영향을 주지 못한 것으로 사료된다.

그림 1 에서 보인 $\mathrm{HBr} / \mathrm{Ar} / \mathrm{CHF}_{3}$ 가스에 대한 식각 특성의 영향과 그림 3. 에서 보인 폴리머 형성 과 같 은 활성종 들의 박막 표면 반응을 좀 더 관찰하기 위 하여 XPS를 이용하여 식각 후 $\mathrm{ZnO}$ 박막의 표면을 분석하였다. 선행 연구 결과에서 알 수 있듯이 그림 4 에서 $\mathrm{Zn} 2 \mathrm{p}-\mathrm{O}$ 피크의 결합 에너지는 $1044.8 \mathrm{eV}$ 이 고, $\mathrm{Zn}-\mathrm{F}$ 로 표면이 결합하게 되면 높은 결합 에너지 로 $1 \mathrm{eV}$ 이동 하게된다 [7,8]. 따라서 $\mathrm{CHF}_{3}$ 혼합비가 증가함에 따라 표면에 폴리머가 형성되었음을 확인할 수 있다.

이와 같은 결과에 의해 $\mathrm{HBr} / \mathrm{Ar} / \mathrm{CHF}_{3}$ 플라즈마에 서 $\mathrm{CHF}_{3}$ 의 혼합비를 증가 하게 되면 표면에 $\mathrm{Zn}-\mathrm{F}$ 결합을 형성하게 되어 표면에 잔류하는 폴리머가 많 아짐에 따라 표면 반응을 방해하여 $\mathrm{CHF}_{3}$ 혼합비가 증가함에 따라 식각속도가 감소하는 것으로 해석 된다.

\section{4. 결 론}

본 연구에서는 $\mathrm{HBr} / \mathrm{Ar} / \mathrm{CHF}_{3}$ 플라즈마에서 $\mathrm{CHF}_{3}$ 
의 혼합비를 증가시키면서 $\mathrm{HBr} / \mathrm{Ar} / \mathrm{CHF}_{3}$ 가스 플라 즈마에 대한 $\mathrm{ZnO}$ 박막의 식각 매커니즘를 연구하였다.

$\mathrm{ZnO}$ 박막의 식각에서는 $\mathrm{Br}$ 에 의한 화학적인 식각 메커니즘이 주요하다. 하지만 $\mathrm{CHF}_{3}$ 혼합비에 따라 식각률이 감소하는 경향을 보였다. 또한 $\mathrm{CHF}_{3}$ 혼합 비가 증가함에 따라 self-bias voltage와 이온 포화전 류는 증가하는 경향을 보였다. QMS 결과에서 fluorine 라디칼의 부분압의 증가를 확인하였다. 플라 즈마 내에서 fluorine 라디칼이 증가하는 것으로 볼 수 있다. XPS 결과에 따라 $\mathrm{ZnO}$ 박막 표면에 fluorine 라디칼에 의해 $\mathrm{Zn}-\mathrm{F}$ 결합의 폴리머가 형성 되면서 표면에 잔류하는 폴리머가 많아짐에 따라 표면 반응 을 방해하여 $\mathrm{CHF}_{3}$ 혼합비가 증가함에 따라 식각속도 가 감소하는 것으로 해석된다.

\section{감사의 글}

이 논문은 2007년도 한서대학교 교비 학술연구 지 원사업에 의하여 연구되었습니다.

\section{REFERENCE}

[1] T. Minami, H. sato, H. Sonohara, S. takata, T. Miyata, and I. Fukuda, Thin solid Films 253, 14 (1994).

[2] J. T. cheung and S. R Johnson, Aerospace Eng. 14, 7 (1994).

[3] H. Gomez, A. Maldonado, R. Asomoza, E.P. Zironi, J. Caneta-Ortega, and J. Palacios Gomez, Thin Soild Films 293, 117 (1997).

[4] S. R. Min, H. N. Cho, Y. L. Li, and C. W. Chung, Thin Solid Films 516, 3521 (2008).

[5] Y.-H. Ham, A. M. Efremov, S. J. Yun, J. K. Kim, N. K. Min, and K.-H. Kwon, Thin Solid Films 517, 4242 (2009).

[6] M. S. Kim, N.-K. Min, S. J. Yun, H. W. Lee, A. Efremov, and K. -H. Kwon, Microelectron. Eng. 85, 348 (2008).

[7] H. K. Kim, J. W. Baea, K. K. Kim, S. J. Park, T. Y. Seong, and I. Adesida, Thin Solid Films 90, 447 (2004).

[8] S. W. Na, M. H. Shin, Y. M. Chung, J. G. Han, and N. E. Lee, J. Vac. Sci. Technol. A 23, 898 (2005). 